$11-2019$

\title{
Assessing the adherence of obstetricians towards postpartum diabetes screening guidelines: A pre- and post-intervention study at secondary care hospital in Karachi, Pakistan
}

Sadiqa Munir Razzaqui

Aga Khan Hospital for Women, Karimabad, Karachi

Neelofur Babar

Aga Khan Hospital for Women, Karimabad, Karachi

Zaib un Nisa Memon

Aga Khan Hospital for Women, Karimabad, Karachi

Sarah Rafiq

Aga Khan University

Follow this and additional works at: https://ecommons.aku.edu/

pakistan_fhs_mc_women_childhealth_obstet_gynaecol

Part of the Obstetrics and Gynecology Commons

\section{Recommended Citation}

Razzaqui, S. M., Babar, N., Nisa Memon, Z. u., Rafiq, S. (2019). Assessing the adherence of obstetricians towards postpartum diabetes screening guidelines: A pre- and post-intervention study at secondary care hospital in Karachi, Pakistan. JPMA. The Journal of the Pakistan Medical Association, 69(11), 1673-1676. Available at: https://ecommons.aku.edu/pakistan_fhs_mc_women_childhealth_obstet_gynaecol/198 
EDUCATION RESEARCH

\title{
Assessing the adherence of obstetricians towards postpartum diabetes screening guidelines: a pre- and post-intervention study at secondary care hospital in Karachi, Pakistan
}

Sadiqa Munir Razzaqui1, Neelofur Babar2, Zaib-un-Nisa Memon³, Sarah Rafiq ${ }^{4}$

\begin{abstract}
Objective: To assess the adherence level of obstetricians towards postpartum diabetes screening guidelines.

Methods: The quasi-experimental pre- and post-intervention study was conducted from May 2014 to April 2015 at Aga Khan Hospital for Women-Karimabad, Karachi, and comprised all obstetricians practicing at the time. All the booked women with gestational diabetes delivered in the 6 months before refresher lecture (group 1) and those delivering in the 6 months following the intervention (group 2) were included. Data was analysed using SPSS 19.

Results: Of the 550 cases, 275(50\%) each were in groups 1 and 2. All pregnant women had live-birth. The intervention made it thrice likely (95\% confidence interval: 7.83 ) that a physician advised postpartum oral glucose tolerance test. Caesarean section increased the chances of getting test advice almost 4 times (95\% confidence interval: 1.70, 9.10) compared to women who delivered vaginally. Women managed on insulin with / without metformin were 4 times likely to being advised the test compared to women managed on diet (confidence interval: 1.00, 17.09). Full-time employees advised 7 times more than the visiting obstetricians (confidence interval: 1.33, 35.16). Conclusion: It is time for more strategic planning regarding patient education the benefits of detection of abnormal glucose tolerance in early postpartum period.
\end{abstract}

Keywords: GDM, Postpartum, Diabetes mellitus screening, OGTT, FBG, Guidelines, Obstetricians. (JPMA 69: 1673; 2019). doi: 10.5455/JPMA.287171.

\section{Introduction}

Worldwide, diabetes mellitus (DM) is currently the fastest growing non-communicable disease and has gained epidemic levels. ${ }^{1}$ Gestational diabetes mellitus (GDM) is a significant risk factor for the development of type 2 diabetes mellitus (T2DM). According to the American Diabetes Association (ADA) GDM is "any degree of glucose intolerance with the onset or first recognition during pregnancy".2 GDM increases the risk of adverse pregnancy consequences, including maternal and perinatal mortality, obstructed labour, infections, spontaneous abortion, congenital abnormalities and macrosomia. ${ }^{3}$ Women with GDM are not only prone to develop T2DM, but also have increased risk of cardiovascular disease later in life.., 5 In addition, children of women with GDM are at increased risk of obesity,

1-3Aga Khan Hospital for Women, Karimabad, Karachi;

${ }^{4}$ Aga Khan University Hospital, Karachi, Pakistan.

Correspondence: Sadiqa Munir Razzaqui. e-mail: sadiqa.razzaqui@aku.edu glucose intolerance, and overt diabetes mellitus (DM) in adult life. 6

The Fifth International Workshop-Conference on GDM recommended intensive postpartum monitoring: Random / fasting blood glucose (FBG) 1-3 days postpartum; oral glucose tolerance test (OGTT) 6-12 weeks later, to be repeated 1 year postpartum and triannually thereafter with annual FBG in between.7 Despite these strategies, it has been noted that postpartum screening rates are low among high-risk mothers and range $23-58 \% .8,9$

Women with GDM-affected pregnancy have a $20 \%$ chance of developing T2DM in the first decade following pregnancy though the risk can be as high as $70 \%$ in higher risk populations. 10,11 Postpartum screening for DM allows for timely interventions to reduce the risk DM as well as to carry out appropriate treatment of its complications in affected women. One of the reasons for low screening rates is failure of the obstetricians to 
advise appropriate test. To improve postpartum screening, there is a need to introduce system factors that facilitate adherence to guidelines.

The current study was planned to assess the adherence of obstetricians to the recommended guidelines for postpartum screening of GDM-affected women.

\section{Subjects and Methods}

The quasi-experimental pre- and post-intervention study was conducted from May 2014 to April 2015 at Aga Khan Hospital for Women-Karimabad (AKHW-K), Karachi, and comprised all obstetricians practicing at the time. It is an outreach secondary care centre of Aga Khan University Hospital (AKUH), Karachi, with a delivery rate around 3,000 per year. Institutional ethics review committee's approval was taken. All women booked for delivery with GDM diagnosed on the basis of FBG $\geq 92 \mathrm{mg} / \mathrm{dl}$ at initial visit and 75gm OGTT.

\section{Diagnostic Reference Values for Gestational Diabetes}

Fasting glucose: $\leq 92 \mathrm{mg} / \mathrm{dl}$

1-hour glucose : $\leq 180 \mathrm{mg} / \mathrm{dl}$

2-hour glucose : $\leq 153 \mathrm{mg} / \mathrm{dl}$

Note: The diagnosis of Gestational Diabetes Mellitus (GDM) is made when any of the above plasma glucose values are exceeded.

Reference: American Diabetic Association Diabetes Care, Jan 2012.35(S1):p.S64-SS71.

between 24 and 32 weeks of gestation were included. Those who delivered in the 6 months before intervention were designated as group 1, and those who delivered in the 6 months after a refresher lecture formed group 2. All obstetricians practising at the centre were assessed for adherence to postpartum DM screening guidelines by reviewing the medical records of patients.

\section{GTT-2 Hrs Interpretation:}

2-h post load glucose $<140 \mathrm{mg} / \mathrm{dl}=$ normal glucose tolerance

2-h post load glucose $140-199 \mathrm{mg} / \mathrm{dl}=$ Impaired glucose tolerance

2-h post load glucose $>200 \mathrm{mg} / \mathrm{dl}=$ Provisional diagnosis of diabetes.

Reference: American Diabetic Association (ADA) 2007

Refresher lecture on postpartum DM screening guidelines was conducted on November 26, 2014, to create awareness and refresh the knowledge. Labour record management system (LRMS) was used to identify women with GDM-affected pregnancy who delivered during the study period. Prospective and retrospective review of the medical records was done. Data was collected on a pre-designed proforma. It included obstetrician's employment status and experience in years. Patient data included age, parity, GDM history, antenatal treatment of GDM (diet control or drug therapy: metformin \pm insulin), family history of diabetes, outcome of pregnancy (livebirth or stillbirth), mode of delivery (vaginal or operative), baby's weight, and OGTT laboratory report. The outcome examined was documented plan of postpartum DM screening in the medical record of women with GDM-affected pregnancy at their $1 \mathrm{st}$ postnatal (PN) visit between 1 st and 2 nd PN weeks. The records were again reviewed at 6-12 weeks postpartum, allowing sufficient time to complete postpartum OGTT and postpartum follow-up visit. These records were examined for documentation of OGTT at 1st PN visit, and availability of OGTT report at 6 weeks PN visit. After initial review of the records and collection of data, the intervention in the shape of the refresher lecture on postpartum DM screening guideline was delivered. The records were reviewed 6 months later for postintervention review which was done on the same pattern as the pre-intervention data. Data was analysed using SPSS 19 December 2, 2016, to October 5, 2017.

\section{Results}

Of the 550 cases, 275(50\%) each were in groups 1 and 2. All pregnant women had live-birth. A total of 352(64\%) women were aged $<30$ and $327(59.5 \%)$ were multiparous. There was no statistical difference between the groups in terms of age, parity, gestational age at delivery and GDM history ( $p>0.05$ each) (Table 1 ).

Logistic regression showed that intervention made it thrice likely (Adjusted odds ratio [AOR]: 3.34; 95\% confidence interval $[\mathrm{CI}] " 1.43,7.83$ ) for the physicians to advise postpartum OGTT. Caesarean section (CS) also increased the chances of getting advised for OGTT almost 4 times (AOR: $3.94 ; 95 \% \mathrm{Cl}: 1.70,9.10)$ compared to women who delivered vaginally. Women managed on insulin with / without metformin were 4 times likely to get advised for OGTT compared to women managed on diet (AOR: $4.14 ; 95 \% \mathrm{Cl}$ : 1.00, 17.09). Full-time employees advised OGTT 7 times more than the visiting obstetricians (Table 2).

\section{Discussion}

Studies have shown that identification of pre-diabetes is important since up to $70 \%$ of these individuals eventually develop T2DM. ${ }^{12}$ Therefore abnormal glucose 
Table-1: Baseline characteristics of pre intervention and post intervention group

\begin{tabular}{|c|c|c|c|}
\hline Variables & $\begin{array}{c}\text { Group } A(n=275) \\
n(\%)\end{array}$ & $\begin{array}{c}\text { Group B (n=275 } \\
n(\%)\end{array}$ & p-value \\
\hline $\begin{array}{l}\text { Age: } \\
<20-30 \text { years } \\
31->40 \text { years }\end{array}$ & $\begin{array}{c}173(62.9) \\
102(37)\end{array}$ & $\begin{array}{c}179(65.1) \\
96(34)\end{array}$ & 0.59 \\
\hline $\begin{array}{l}\text { Mode of delivery: } \\
\text { Vaginal } \\
\text { Caesarean section }\end{array}$ & $\begin{array}{l}152(55.3) \\
123(44.7)\end{array}$ & $\begin{array}{l}125(45.5) \\
150(54.5)\end{array}$ & 0.02 \\
\hline $\begin{array}{l}\text { Parity: } \\
\text { Primiparous } \\
\text { Multiparous }\end{array}$ & $\begin{array}{l}105(38.2) \\
170(61.8)\end{array}$ & $\begin{array}{l}118(42.9) \\
157(57.1)\end{array}$ & 0.25 \\
\hline $\begin{array}{l}\text { Family history of GDM: } \\
\text { Yes } \\
\text { No }\end{array}$ & $\begin{array}{l}156(56.9) \\
119(43.1)\end{array}$ & $\begin{array}{l}184(66.9) \\
91(33.1)\end{array}$ & 0.01 \\
\hline $\begin{array}{l}\text { History of GDM: } \\
\text { Yes } \\
\text { No }\end{array}$ & $\begin{array}{l}27(32.1) \\
57(67.9)\end{array}$ & $\begin{array}{l}35(43.8) \\
45(56.3)\end{array}$ & 0.12 \\
\hline $\begin{array}{l}\text { Gestational age at delivery: } \\
<37 \text { weeks } \\
37-40 \text { weeks }\end{array}$ & $\begin{array}{c}24(8.7) \\
251(91.3)\end{array}$ & $\begin{array}{c}24(8.7) \\
251(91.3)\end{array}$ & 1.00 \\
\hline $\begin{array}{l}\text { Antenatal sugar control meth } \\
\text { Diet } \\
\text { Metformin } \\
\text { Insulin with/without Metofrmin }\end{array}$ & $\begin{array}{l}138(50.2) \\
108(39.3)\end{array}$ & $\begin{array}{c}88(32) \\
158(57.5)\end{array}$ & 0.00 \\
\hline $\begin{array}{l}\text { First visit postpartum: } \\
\text { Yes } \\
\text { No }\end{array}$ & $\begin{array}{c}219(79.6) \\
56(20.4)\end{array}$ & $\begin{array}{c}236(85.8) \\
39(14.2)\end{array}$ & 0.05 \\
\hline $\begin{array}{l}\text { Second visit postpartum: } \\
\text { Yes } \\
\text { No }\end{array}$ & $\begin{array}{l}66(52.8) \\
209(76)\end{array}$ & $\begin{array}{c}59(21.5) \\
216(78.5) \\
\end{array}$ & 0.47 \\
\hline
\end{tabular}

order for postpartum OGTT which increased to $50.9 \%$ post-intervention. Although the obstetricians' rate of advising postpartum OGTT increased, the overall rate still remained low.

Several factors were noted during the study that influenced postpartum OGTT advice.

Women with GDM who had CS were four times more likely to get advice for OGTT testing compared to women who delivered vaginally as almost all these women had 1 st postoperative visit for the removal of stitches. Also, it was evident that GDM women who were treated with metformin alone, metformin-and-insulin or insulin alone were given requisition for postpartum OGTT testing. Several studies have shown similar effect, ${ }^{14}$ while other studies have shown contrary result. ${ }^{15}$

One of the reasons that patients were not advised postpartum OGTT seemed to be that patients did not return for follow-up. Other studies 16 also showed that attendance at postpartum clinics was a very important factor in glucose testing. This calls for looking into the factors leading to non-compliance on the part of the patients as well.

Interestingly, it was found that full-time faculty was more compliant towards DM screening guidelines compared to the visiting obstetricians, and the

Table-2: Factors associated with physician's advice for 0GTT during postpartum period $(n=550)$.

\begin{tabular}{lcccc}
\hline Variables & \multicolumn{2}{c}{ Advice for postpartum 0GTT } & Crude OR & Adjusted OR \\
& No [n (\%)] & Yes [n (\%)] & (95\% C.I) & (95\% C.I) \\
\hline $\begin{array}{l}\text { Group A } \\
\text { Group B }\end{array}$ & $199(72.4)$ & $76(27.6)$ & 1 & 1 \\
Family history of DM: & $135(49.1)$ & $140(50.9)$ & $2.71(1.90,3.87)$ & $3.34(1.43,7.83)$ \\
No & & & & \\
Yes & $138(66)$ & $71(34)$ & 1 & 1 \\
History of GDM: & $195(57.4)$ & $145(42.6)$ & $1.44(1.01,2.06)$ & $1.90(.79,4.61)$ \\
No & & & & \\
Yes & $77(75.5)$ & $25(24.5)$ & 1 & 1 \\
Mode of delivery: & $41(66.1)$ & $21(33.9)$ & $1.57(.78,3.15)$ & $.70(.30,1.63)$ \\
Vaginal & & & & \\
Cesarean section & $192(69.3)$ & $85(30.7)$ & 1 & 1 \\
Antenatal sugar control method: & $142(52)$ & $131(48)$ & $2.08(1.47,2.95)$ & $3.94(1.70,9.10)$ \\
Diet & $170(75.2)$ & $56(24.8)$ & 1 & \\
Metformin & $137(51.5)$ & $129(48.5)$ & $2.85(1.94,4.20)$ & $3.95(1.58,9.85)$ \\
Insulin with/without metofrmin & $27(46.6)$ & $31(53.4)$ & $3.48(1.91,6.33)$ & $4.14(1.00,17.09)$ \\
Employee status: & & & & \\
Full time & $287(59.3)$ & $197(40.7)$ & 1 & 1 \\
Part time & $47(71.2)$ & $19(28.8)$ & $1.69(.96,2.98)$ & $6.85(1.33,35.16)$ \\
\hline
\end{tabular}

OGTT: Oral glucose tolerance test, OR: 0dds ratio, $\mathrm{Cl}$ : Confidence interval.

homeostasis antenatally poses increased risk of future DM. ${ }^{13}$

The current study found that during the pre-intervention period, $27.6 \%$ women with GDM received a documented rate of advising GTT increased significantly after intervention.

Another factor is that though obstetricians advised OGTT, patients had it performed at another laboratory outside our centre whose results may or may not be available in medical records.

The current study has its limitations as it was only a medical chart review and, therefore, it could not determine whether defects in testing were attributable to patients, physicians or healthcare system barriers; or to all three combined. Also, since it is a single-centre study, the findings are not generalisable.

\section{Conclusion}

Adherence of obstetrician to postpartum DM screening guidelines improved after intervention, but overall rate of postpartum DM screening was still low. Apart from encouraging the physicians, there is also a need for educating the patients in this regard. 
Disclaimer: None.

\section{Conflict of Interest: None.} Source of Funding: None.

\section{References}

1. Nanditha A, Ma RC, Ramachandran A, Snehalatha C, Chan JC, Chia $\mathrm{KS}$, et al. Diabetes in Asia and the Pacific: Implications for the Global Epidemic. Diabetes care 2016; 39: 472-85.

2. American Diabetes Association. Diagnosis and classification of diabetes mellitus. Diabetes Care 2014; 37(Supplement 1): S81-S90.

3. Nielsen KK, Courten Md, Kapur A. The urgent need for universally applicable simple screening procedures and diagnostic criteria for gestational diabetes mellitusâ€"lessons from projects funded by the World Diabetes Foundation. Global Health Action 2012; 5: 17277.

4. Vambergue A, Dognin C, Boulogne A, Rejou MC, Biausque S, Fontaine $P$. Increasing incidence of abnormal glucose tolerance in women with prior abnormal glucose tolerance during pregnancy: DIAGEST 2 study. Diabet Med 2008; 25: 58-64.

5. Retnakaran R, Shah BR. Mild glucose intolerance in pregnancy and risk of cardiovascular disease: a population-based cohort study. CMAJ 2009; 181: 371-6.

6. Clausen TD, Mathiesen ER, Hansen T, Pedersen O, Jensen DM, Lauenborg J, et al. High prevalence of type 2 diabetes and prediabetes in adult offspring of women with gestational diabetes mellitus or type 1 diabetes. Diabetes Care 2008; 31: 340-6.

7. Metzger BE, Buchanan TA, Coustan DR, De Leiva A, Dunger DB, Hadden DR, et al. Summary and recommendations of the fifth international workshop-conference on gestational diabetes mellitus. Diabetes Care 2007; 30(Supplement 2): S251-S60.
8. Ferrara A, Peng T, Kim C. Trends in postpartum diabetes screening and subsequent diabetes and impaired fasting glucose among women with histories of gestational diabetes mellitus. Diabetes Care 2009; 32: 269-74.

9. Almario CV, Ecker T, Moroz LA, Bucovetsky L, Berghella V, Baxter JK. Obstetricians seldom provide postpartum diabetes screening for women with gestational diabetes. Am J Obstet Gynecol 2008; 198: 528.

10. Feig DS, Zinman B, Wang X, Hux JE. Risk of development of diabetes mellitus after diagnosis of gestational diabetes. CMAJ 2008; 179: 229-34.

11. Kim SY, England L, Wilson HG, Bish C, Satten GA, Dietz P. Percentage of gestational diabetes mellitus attributable to overweight and obesity. Am J Public Health 2010; 100: 1047-52.

12. Nathan DM, Davidson MB, DeFronzo RA, Heine RJ, Henry RR, Pratley $R$, et al. Impaired fasting glucose and impaired glucose tolerance: implications for care. Diabetes Care 2007; 30: 753-9.

13. Carr DB, Newton KM, Utzschneider KM, Tong J, Gerchman F, Kahn $\mathrm{SE}$, et al. Modestly elevated glucose levels during pregnancy are associated with a higher risk of future diabetes among women without gestational diabetes mellitus. Diabetes Care 2008; 31: 1037-9.

14. Nielsen KK, Kapur A, Damm P, De Courten M, Bygbjerg IC. From screening to postpartum follow-upâ€"the determinants and barriers for gestational diabetes mellitus (GDM) services, a systematic review. BMC pregnancy Childbirth 2014; 14: 41.

15. Hunt KJ, Conway DL. Who returns for postpartum glucose screening following gestational diabetes mellitus? Am J Obstet Gynecol 2008; 198: 404.

16. Russell MA, Phipps MG, Olson CL, Welch HG, Carpenter MW. Rates of postpartum glucose testing after gestational diabetes mellitus. Obstet Gynecol 2006; 108: 1456-62. 